\title{
BILATERAL CORACO-CLAVICULAR ARTICULATIONS IN THE AUSTRALIAN ABORIGINAL
}

\author{
L. J. Ray, Melbourne, Australia \\ From the Department of Anatomy and Histology, University of Melbourne
}

During the course of a metrical and non-metrical study of the clavicle of the Australian aboriginal one pair of bones out of the 292 clavicles examined showed features of the conoid tuberosity well beyond the normal range of variation. These features were reflected also in the corresponding coracoid processes of the scapulae and indicated that, in life, these bones had been in articulation.

The skeleton was that of a male and the bones were in good condition.

\section{THE CLAVICLES}

The atypical features were present in both clavicles with only slight differences in the dimensions of the articular facets on each side (Table I).

TABLE I

Dimensions of the Articular facets on the Clavicles

\begin{tabular}{|lcc|}
\hline & \multicolumn{2}{c|}{ Measurement (millimetres) } \\
\hline & Right & Left \\
\cline { 2 - 3 } Long axis (medial to lateral) & 12 & 15 \\
Short axis (antero-posterior) & 6 & 9 \\
\hline
\end{tabular}

The under surface of the bone presented a well marked subclavian groove, the posterior lip of which was accentuated over its lateral third. The conoid tuberosity was clearly separable

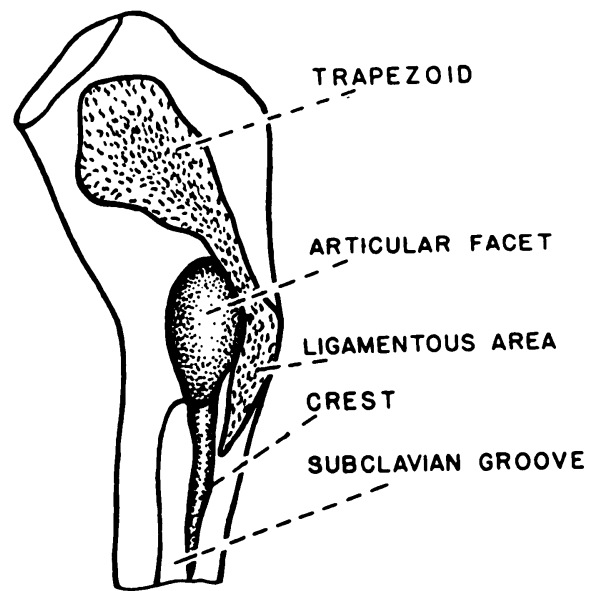

Fig. 1

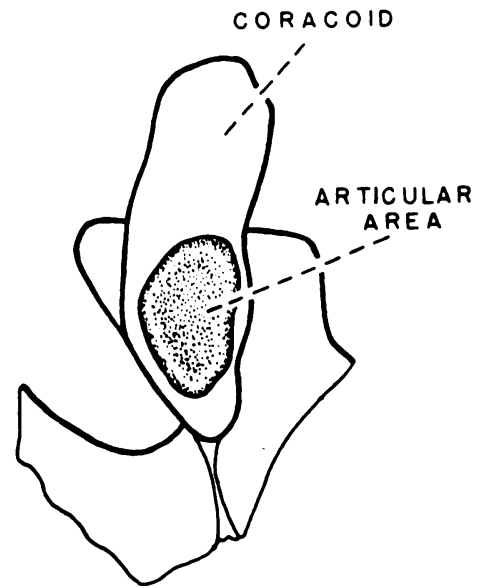

Fig. 2

Figure 1-Lateral end of left clavicle from below. Figure 2-Upper surface of coracoid process of left scapula.

into two parts. The posterior part was roughened and faced obliquely backwards and down wards: traced laterally this part was continuous with the postero-medial limit of the marking for the 


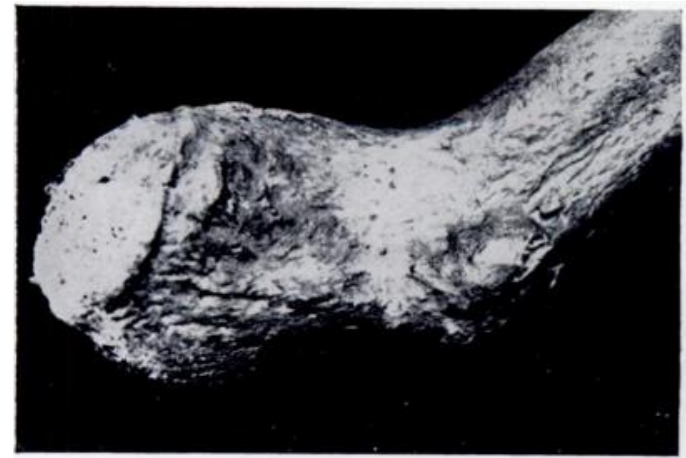

FIG. 3

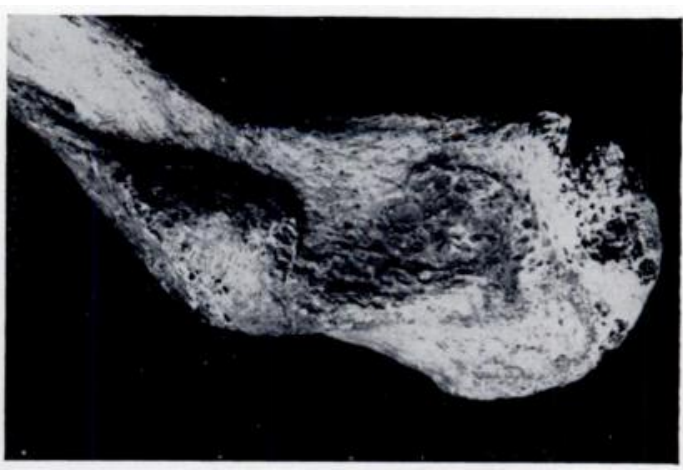

Fig. 4

Right and left clavicles showing the articular facet on the conoid tuberosity of each.

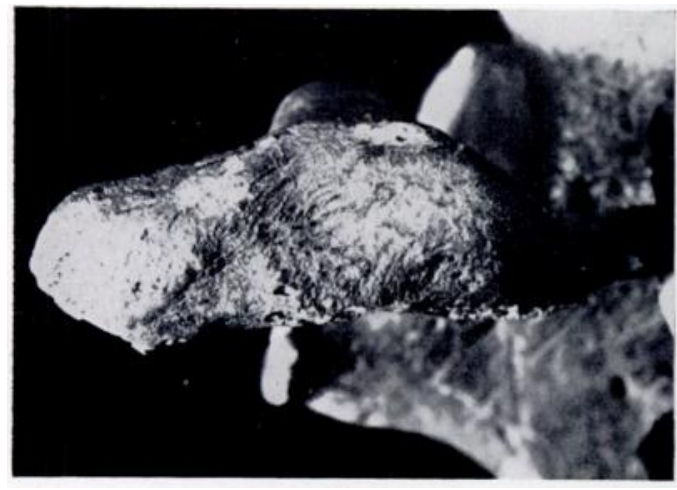

Fig. 5

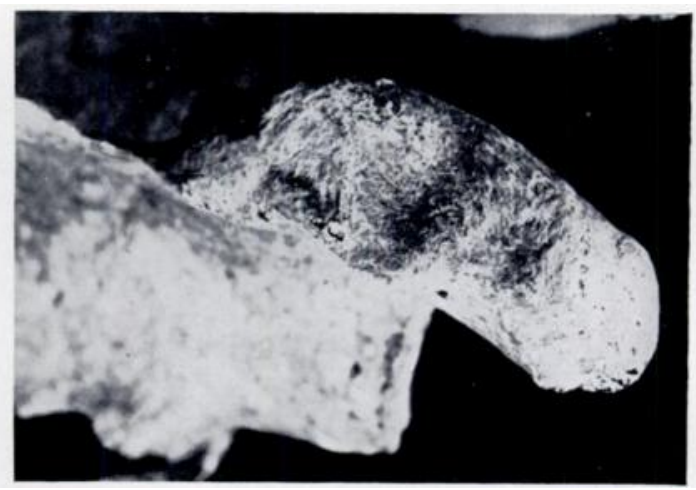

Fig. 6

Right and left coracoid processes showing the articular area on each.

trapezoid liagment. The anterior part of the tuberosity was discrete and presented a smooth surface facing forwards and downwards. It was slightly convex from before backwards and more so from side to side (Figs. 1, 3 and 4).

\section{THE SCAPULAE}

Each coracoid process was of normal general shape, but showed a definite reniform depression on the upper surface near the medial end (Figs. 2, 5 and 6). When the clavicle and scapula were articulated, this depression was immediately opposed to the smooth facet on the conoid tuberosity. The depression was smoother than the rest of the upper surface of the coracoid, but not so smooth as the corresponding conoid tuberosities. The differences between right and left were again in size only, and slight (Table II).

\section{TABLE II}

Dimensions of the Articular facets on the Coracoid Processes

\begin{tabular}{|lcc|}
\hline & $\frac{2}{\text { Measurement (millimetres) }}$ \\
\cline { 3 - 4 } & $\frac{\text { Right }}{\text { Left }}$ & $\frac{18}{19}$ \\
Short axis (at right angles to axis of coracoid) & 13 & 13 \\
\hline
\end{tabular}

On casual observation the depressions on the upper surface of the coracoid processes might easily be overlooked, unlike those on the clavicles.

VOL. 41 B, No. 1, FEBRUARY 1959 


\section{THE ARTICULATED BONES}

When the bones were articulated the smooth area of the conoid was facing towards the corresponding area of the coracoid process, but separated from it by a few millimetres-a distance that was not great enough to preclude a direct articulation during life.

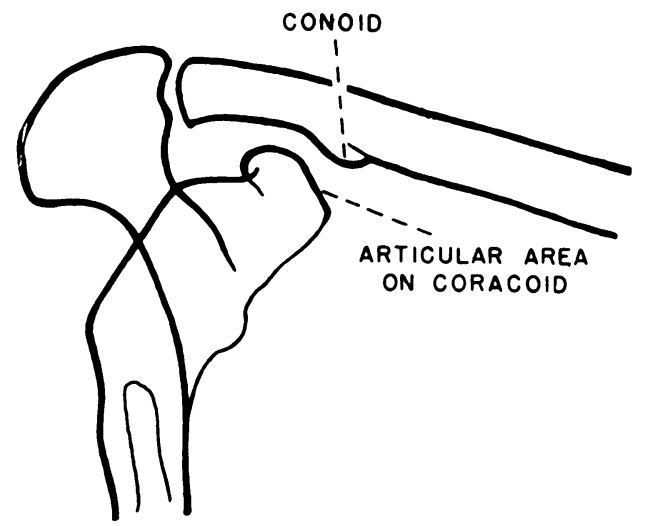

FIG. 7

Tracing of a radiograph of the right clavicle and scapula.

The articulated bones were radiographed and a tracing is shown in Figure 7. It will be noticed that the conoid does not appear to be unduly large, and the appearance might easily pass as within normal limits. However, the features of the dried bone certainly indicate the presence of an articulation. Perhaps in this observation lies the answer to the difference of opinion that exists about the rarity of this abnormal joint.

\section{DISCUSSION}

A survey of the literature reveals conflicting evidence on the occurrence of a coracoclavicular joint in man.

Two aspects of the problem require consideration. The first concerns the frequency of the condition and the second the nature of the joint. According to Hall (1950), only fifty-four cases have been reported in the world literature, most of these having been discovered

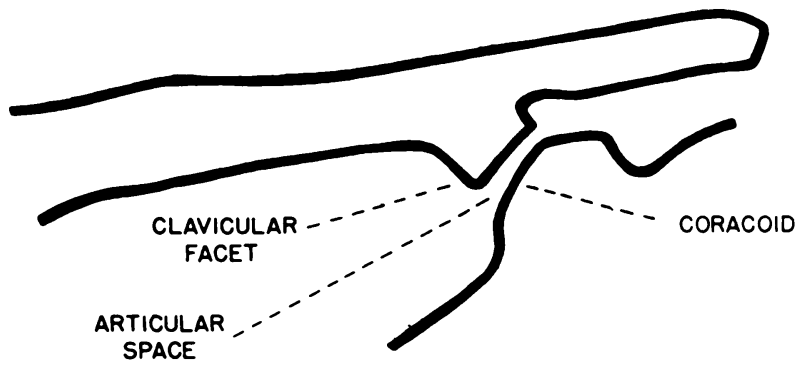

Fig. 8

Tracing of coraco-clavicular articulation illustrated by Wertheimer (1948).

accidentally either at necropsy or during radiological examination for some other reason. Other authors have also emphasised the rarity of the condition, and Wertheimer (1948) analysed the recorded cases. Other authorities, however, have stated or implied that the condition is not rare (Nutter 1941. Poirier and Charpy 1899, Lane 1888). 
Before the advent of radiography cases reported were those encountered at necropsy or during anatomical dissections. After the introduction of radiography most of the reported

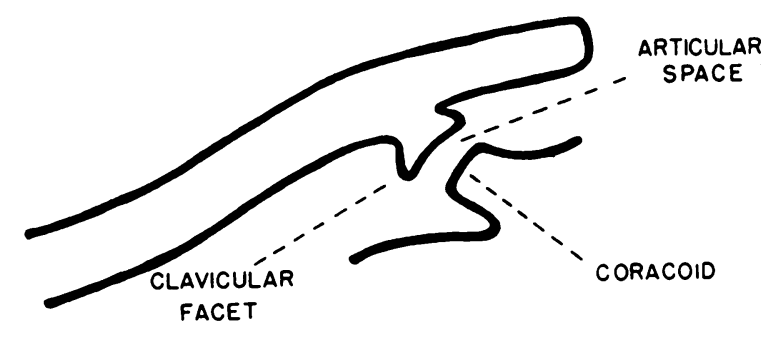

Fig. 9

Tracings of coraco-clavicular articulation illustrated by Nutter (1941) with a well developed conoid facet.

examples have been either noticed accidentally or have been discovered only when a detailed study of the shoulder has been made for some painful condition, the cause of which was not

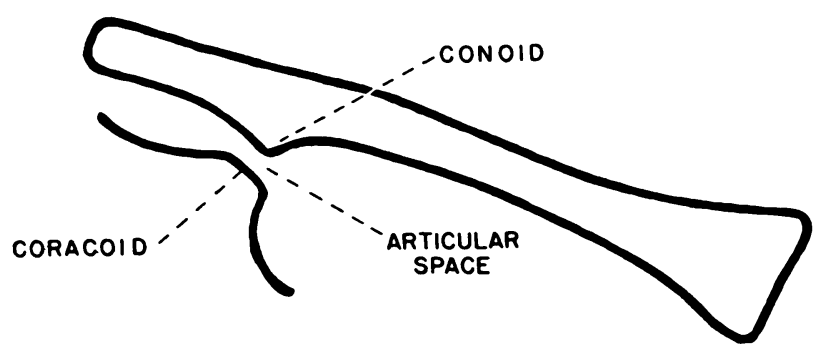

Fig. 10

Another coraco-clavicular articulation illustrated by Nutter (loc. cit.), but with a small conoid facet.

immediately demonstrable (Hall 1950, Gradoyevitch 1939, Wertheimer 1948). Nutter, on the other hand, approached the problem in a more analytical fashion and was presumably aware

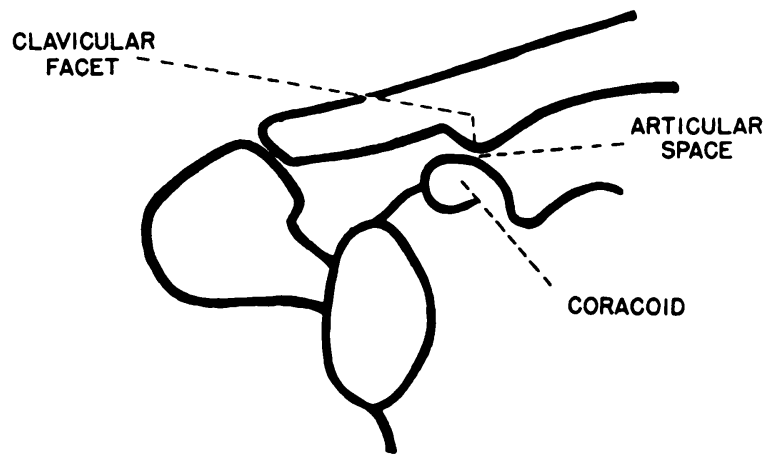

Fig. 11

Tracing of a coraco-clavicular articulation illustrated by Miessen. The conoid facet is small.

of the possibility of this condition when he examined his films. This accounts for his report of a much higher incidence than other workers.

The examples illustrated by Wertheimer (Fig. 8) and Hall had a very large conoid tuberosity with a well marked flattened facet at its apex. In such a case the conoid tuberosity 
is obviously unusual and the diagnosis of the atypical joint is well established. A similar case was illustrated by Nutter (Fig. 9) but, in addition, he also illustrated a joint that was not so obvious (Fig. 10). The latter case is very like the ones reported here. It is also interesting that reports of actual dissections (Gowland 1915, Miessen 1937, Schlyvitch 1937) contain descriptions of the bones which are like the cases now described (Fig. 11). One of the three cases reported by Meyer (1915) is also similar, but his other cases were associated with excessive bone formation which would make radiographic diagnosis obvious.

It seems clear, then, that if the joint is present but the bony surfaces are not exaggerated, its presence may easily be overlooked. In these conditions one must agree with Nutter that "the anatomical and physiological significance of these joints is only academic. However, inasmuch as they are true joints, it can be presumed that they are not exempt from any of the various pathological conditions which affect any other joint." It is possible, too, that sometimes this joint, especially when it is pathological, may interfere with the mechanics of the shoulder girdle. Whether one can agree with Frassetto (1921), who regarded its presence as predisposing to fractures of the surgical neck of the humerus, is doubtful.

The possible existence of this abnormal joint should be borne in mind especially in cases of shoulder pain, or limitation of shoulder movement, in which the cause is obscure.

\section{SUMMARY}

1. A pair of clavicles and the corresponding scapulae were found to possess definite articular facets indicating the presence, in life, of a coraco-clavicular joint.

2. The bones are described and illustrated.

3. These cases are compared with others reported in the literature.

I would like to express my thanks to Mr George Murray Black, who collected the specimens used in this survey, and to Professor S. Sunderland for his advice in the preparation of this paper.

\section{REFERENCES}

Frassetto, F. (1921): Cited by Wertheimer.

Gowland, W. P. (1915): Preliminary Note on a Diarthrodial Articulation between the Clavicle and the Coracoid. Journal of Anatomy and Physiology, 49, 187.

GraDOYEvitCh, B. (1939): Coracoclavicular Joint. Journal of Bone and Joint Surgery, 21, 918.

HALL, F. J. S. (1950): Coracoclavicular Joint. British Medical Journal, i, 766.

LANe, W. A. (1888): The Anatomy and Physiology of the Shoemaker. Journal of Anatomy and Physiology, 22, 593.

Meyer, A. W. (1915): Anatomical Specimens of Unusual Clinical Interest. American Journal of Orthopaedic Surgery, 13, 86.

Miessen, E. (1937): Ein Fall von doppelseitiger Gelenkbildung zwischen Clavicula und Processus coracoides. Anatomischer Anzeiger, 83, 392.

NutTer, P. D. (1941): Coracoclavicular Articulations. Journal of Bone and Joint Surgery, 23, 177.

Poirier, P., and Charpy, A. (1899): Traité d'anatomie humaine. Deuxième édition. Tome I, p. 612. Paris: Masson et Cie.

SCHLYVITCH, B. (1937): Uber den Articulus coracoclavicularis. Anatomischer Anzeiger, 85, 89.

WeRTHEIMER, L. G. (1948): Coracoclavicular Joint. Journal of Bone and Joint Surgery, 30-A, 570. 